\title{
Strict CV without government
}

\author{
Guillaume Enguehard \\ University of Orléans (LLL) \\ g.enguehard@gmail.com
}

\begin{abstract}
In this paper, I aim to unify the Empty Category Principle of Government Phonology with another (more general) principle: the Obligatory Contour Principle. I show that these principles share numerous structural properties: (i) they prevent sequences of identical entities, and (ii) they trigger the same repair mechanisms. The main difference is substantial: ECP handles empty syllabic components, when OCP handles phonological features. I propose to broaden the definition of OCP in including all phonological entities and I show to what extent this definition can account for the effects of ECP. Finally, I point out that this analysis can also account for some specificities of word-edges.
\end{abstract}

Keywords: CVCV; government; Obligatory Contour Principle; epenthesis; dissimilation

\section{Introduction}

This analysis is part of a larger project to develop a strict CV framework (Lowenstamm 1996; Scheer 2004) without the lateral relations inherited from Government Phonology (Kaye et al. 1990). In this paper, I specifically focus on the role of government in the organization of the skeletal level and the limitation of consonant clusters. I argue that this relation is an avatar of a more general autosegmental principle: the Obligatory Contour Principle.

In the Strict CV framework introduced in Lowenstamm (1996), the skeleton is represented with a periodic repetition of $\mathrm{CV}$ units. $\mathrm{C}$ and $\mathrm{V}$ positions (which represent onsets and nuclei respectively) can be filled or empty. However, in order to restrict the number of empty nuclei, Kaye et al. (1990) proposed the Empty Category Principle. This principle states that a nucleic position cannot remain empty if it is not "governed" by a full nucleus on its right.

In the first section, I show that the Empty Category Principle and the Obligatory Contour Principle share common structural properties. In the second section, I propose to represent epenthesis as a dissimilation between two empty syllabic positions. In the third section, I show how this hypothesis predicts some specificities of the phonology observed at word-edges. 


\section{Theoretical context}

In this section, I present the basics of the Empty Category Principle (ECP) and the Obligatory Contour Principle (OCP). I show that these introduce: (i) similar generalizations, and (ii) common repair mechanisms.

\subsection{Empty Category Principle}

As mentioned in the introduction, the ECP was proposed in Kaye et al. (1990) in order to limit the amount of empty nuclei inherent to the representation of consonant clusters. See the Strict CV representation of laptop in (1). Due to the periodicity of $\mathrm{C}$ and $\mathrm{V}$ positions advocated in Lowenstamm (1996), this word is represented with empty nuclei (i.e., empty V positions) on the right of codas.

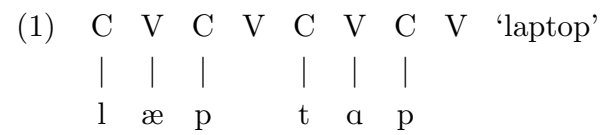

This representation illustrates the possibility for syllabic positions to be empty. However, empirical data shows that this possibility should be limited by the theory. Indeed, consonant clusters are most often limited to two segments (except in case of branching onsets, see e.g., Scheer 1996; Carvalho 2002 or Lowenstamm 2003). In French, this restriction was already mentioned in the Loi des trois consonnes of Grammont (1914). Following this law, the realization of an orthographic $\langle\mathrm{e}\rangle$ (which usually drops) is necessary when it serves to avoid a succession of three consonants. For instance, see French words in (2). In (2a), $\langle\mathrm{e}\rangle$ can be unrealized because its absence results in a CC cluster. In $(2 \mathrm{~b}),\langle\mathrm{e}\rangle$ cannot be unrealized because its absence results in a $\mathrm{CCC}$ cluster.

\begin{tabular}{|c|c|c|}
\hline $\mathrm{VC}\langle\mathrm{e}\rangle \mathrm{CV}$ & & Gloss \\
\hline vaguement & 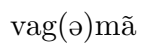 & 'vaguely' \\
\hline seulement & 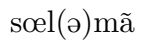 & 'only' \\
\hline faussement & fos(ə)mã & 'wrongly' \\
\hline samedi & $\operatorname{sam}(ə) \mathrm{di}$ & 'Saturday' \\
\hline
\end{tabular}
b. $\mathrm{VCC}\langle\mathrm{e}\rangle \mathrm{CV}$ autrement simplement tristement vendredi

\begin{tabular}{|c|c|}
\hline & Gloss \\
\hline *ots(ə)mã & 'otherwise' \\
\hline *s̃̃pl(ə)mã & 'simply' \\
\hline *tвist(ə)mã & 'sadly' \\
\hline vãds(ə)di & 'Friday' \\
\hline
\end{tabular}

(Delattre 1951) 
The CCC cluster of an ill-formed word like *[otsmã] implies two successive empty nuclei (3).

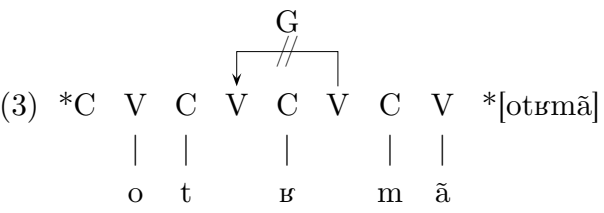

In order to rule out such a configuration, Kaye et al. (1990) proposed the principle (4).

(4) Empty Category Principle

A position may be uninterpreted phonetically iff it is properly governed.

According to this principle, an empty nucleus should be governed (i.e., followed) by a non empty nucleus on its right. When this is not the case (as in (3)), the representation should be repaired. Two repair mechanisms are attested in French: (i) a vowel is associated to one of the empty nuclei ${ }^{1}$ (5a), or (ii) a CV slot is removed (hatched in (5b)).

$\begin{array}{llllllllllll}(5) & \text { a. } & \mathrm{C} & \mathrm{V} & \mathrm{C} & \mathrm{V} & \mathrm{C} & \mathrm{V} & \mathrm{C} & \mathrm{V} & \text { [оtьəmã }] \\ & & & \mid & \mid & & & \mid & \vdots & \mid & \mid & \end{array}$

$\begin{array}{llllll}0 & \mathrm{t} & \boldsymbol{B} & \text { ə } & \mathrm{m} & \tilde{a}\end{array}$

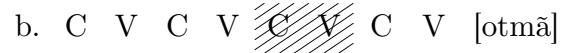

o t $m$ ã

To sum up, the Empty Category Principle aims to prevent a sequence of two empty nuclei by means of addition or deletion. In the next section, I show that the properties of the Obligatory Contour Principle are pretty much the same.

${ }^{1}$ Following the definition of ECP in (4), one can expect a left-insertion of the schwa. Scheer (2001) explains the French right-insertion by the lexical presence of a floating vowel. I set this issue aside for now (see section 2.2 for discussion). 


\subsection{Obligatory Contour Principle}

I now move on to the basics of OCP. This principle was first proposed in Leben (1973) in order to account for dissimilative processes in tonal representations. McCarthy (1986) proposed to broaden its scope in covering segmental units. The definition he suggested is given in (6).

(6) Obligatory Contour Principle (McCarthy 1986, 208)

At the melodic level, adjacent identical elements are prohibited.

Like ECP, OCP involves two entities. These can be found in local adjunction, or they can interact at a distance. As an example of the first case, see the realization of the plural suffix in English mentioned in Anderson $(1974,58)$ and Yip $(1988,86)(7)$. The suffix $\langle-\mathrm{s}\rangle$ is realized as $[\mathrm{s}]$ or $[\mathrm{z}]$ when it is preceded by a consonant with a different place feature or a different mode feature (7a), but it is realized as [Iz] when it is preceded by a consonant that shares both its mode feature and its place feature (7b). In order to account for this phenomenon, Yip (1988) suggested that the distribution of $[\mathrm{I}]$ is controlled by OCP in (6). It occurs in order to prevent a succession of identical feature matrices (i.e., $[+$ coronal $]$ and $[+$ fricative $]$ ).

$$
\begin{array}{lll} 
& \text { Underlying form } & \text { Surface form } \\
\text { a. } & \langle\text { cliff }\rangle\langle\text {-s }\rangle & {[\text { klif-s }]} \\
& \langle\text { bed }\rangle\langle\text {-s }\rangle & {[\text { bed-z }]} \\
\text { b. } & \langle\text { fish }\rangle\langle\text {-s }\rangle & {\left[\text { fr } \int-\text { Iz }\right]} \\
& \langle\text { buzz }\rangle\langle\text {-s }\rangle & {[\text { b } \Lambda \text {-Iz }]}
\end{array}
$$

An example of OCP effect at a distance can be found in the realization of the Latin adjectival suffix 〈-alis〉 (Steriade 1987) (8). Words with the suffix $\langle$-alis can be found in (8a). When the stem contains an /l/ (8b), the lateral feature of the $/ 1 /$ in $\langle$-alis $\rangle$ is removed: the surface form is $\langle$-aris $\rangle$. Finally, when an $\langle\mathrm{r}\rangle$ occurs between the suffix and a preceding $/ 1 /$, the default realization of the suffix is maintained (8c). Steriade (1987) assumed that the distribution of the lateral feature in the adjectival suffix is conditioned by OCP: it can occur iff it is not preceded by another [+lateral] feature on the same tier. The presence of an $/ \mathrm{r} /$, which contains a specified [-lateral] feature, neutralizes the adjacency of the two lateral consonants. 
(8)

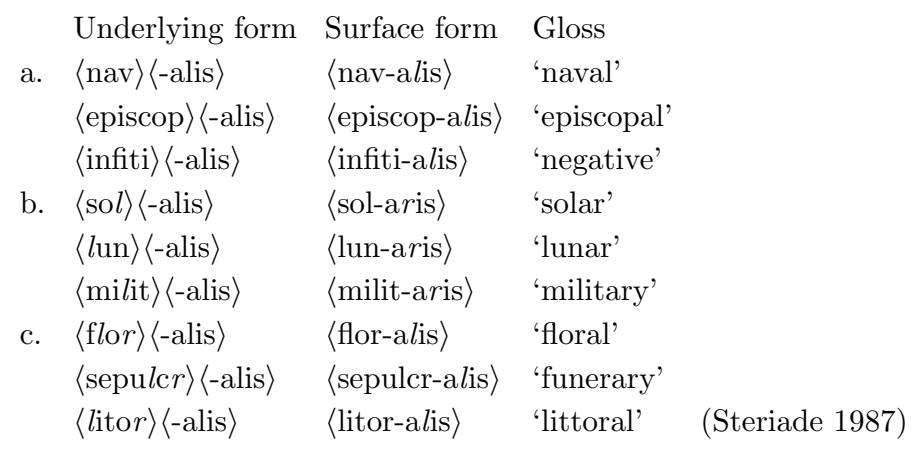

In this example, we see that OCP can apply at a distance in the sphere of consonants. But the same can also apply between nuclei (9). Avanesov (1949) mentions that some Russian dialects show a vowel reduction conditioned by the quality of the following nucleus. This is called Dissimilative Akanye. When the following vowel is not [a], a pretonic vowel $\{a, 0\}$ is realized as [a] (italicised) (9a) (stressed nuclei are underlined). But when the following vowel is [a], a pretonic vowel $\{a, o\}$ is realized as [ə] (9b). This phenomenon can be accounted for with OCP. A pretonic vowel $\{a, o\}$ is realized as [ə] (instead of [a]) before an [a] in order to prevent a succession of identical vowels in adjacent nuclei.

\begin{tabular}{|c|c|c|}
\hline & Dissimilative Akanye & Gloss \\
\hline a. & {$[\mathrm{n} a \mathrm{\gamma}-\mathrm{oj}]$} & 'foot' (instrumental) \\
\hline & [trav-u] & 'grass' (accusative) \\
\hline & [ska3-i] & 'say!' \\
\hline b. & [nวy-a] & 'foot' \\
\hline & {$[\operatorname{tr} \partial v-\underline{a}]$} & 'grass' \\
\hline & [skəz-all] & 'he said' \\
\hline
\end{tabular}

(Avanesov 1949)

In autosegmental phonology, it is often assumed that relevant features are distributed on separated tiers (see e.g., Clements 1985; Archangeli 1985; Hume 1992; Odden 1994, among others). Thus, features can communicate if they are adjacent on a given tier. The accurate organization of these tiers is an orthogonal issue. It can be schematically assumed that vowels and consonants are (at least partially) segregated. Now, it is worth pointing out that both OCP and government can apply on the vowel tier.

The other common property of ECP and OCP is that they both aim to prevent sequences of identical entities. In the case of ECP, these entities are empty nuclei. In the case of OCP, these entities are relevant features. When these principles are not satisfied, repair mechanisms can apply. We saw that violations of ECP are repaired by means of addition or deletion. These 
two mechanisms are also shared by OCP. In the English case mentioned in (7), the succession of identical feature matrices is blocked by means of an epenthesis (10a). In the Latin case mentioned in (8), the succession of $[+$ lateral $]$ features is prevented by the loss of the second one $(10 \mathrm{~b})$.

\begin{tabular}{|c|c|c|c|c|c|c|c|c|c|}
\hline \multirow{3}{*}{\multicolumn{2}{|c|}{ (10) a. }} & $\mathrm{V}$ & $\mathrm{C}$ & $\mathrm{V}$ & $\mathrm{C}$ & V & \multicolumn{2}{|c|}{$\left[\mathrm{fr} \int \mathrm{Iz}\right]$} & \\
\hline & | & | & | & $\vdots$ & 1 & & & & \\
\hline & $\mathrm{f}$ & I & $\begin{array}{c}\int \\
+ \text { cor } \\
+ \text { fric. }\end{array}$ & I & $\begin{array}{c}\mathrm{z} \\
+ \text { cor. } \\
+ \text { fric. }\end{array}$ & & & & \\
\hline b. & $\mathrm{C}$ & $\mathrm{V}$ & $\mathrm{C}$ & $\mathrm{V}$ & $\mathrm{C}$ & V & $\mathrm{C}$ & V & $\langle$ solaris $\rangle$ \\
\hline & | & | & | & 1 & 1 & | & | & & \\
\hline & $\mathrm{s}$ & o & $\begin{array}{c}1 \\
+ \text { lat. }\end{array}$ & $\mathrm{a}$ & $\begin{array}{l}\text { r } \\
\text { lat. }\end{array}$ & $\mathrm{i}$ & $\mathrm{s}$ & & \\
\hline
\end{tabular}

To summarize, we saw that ECP and OCP share various structural properties: (i) they both aim to avoid successions of identical entities, (ii) they both can apply at a distance, and (iii) they both involve repair mechanisms such as addition or deletion of phonological material. The main difference between these two principles is substantial: ECP handles empty categories, while OCP handles phonological features. In the following section, I propose to unify these two principles by extending the definition of OCP.

\section{Proposal}

In this section, I show that it is possible to account for the restrictions on consonant clusters with the theoretical device represented by OCP. For this, I propose to broaden the definition of OCP in order to include all phonological entities.

\subsection{Reformulation of $\mathrm{OCP}$}

In the definition given in McCarthy (1986) (6), OCP concerns only melodic features. However, this OCP constraint has avatars in other dimensions of phonology. In the metrical dimension, Prince (1983) proposed to account for the rhythmic aspect of stress (i.e., a strict succession of strong and weak positions) by means of a "stress clash" constraint that avoids "a too great proximity of elements at the same level" (Prince 1983, 21). In the skeletal 
dimension, Carvalho (2002, 22-23) suggested that the periodicity of $\mathrm{C}$ and $\mathrm{V}$ positions in the skeleton is due to an OCP effect at the skeletal level (I will come back to this point subsequently). In this context, I propose a reformulation of OCP that includes all the phonological entities. This reformulation is given in (11).

(11) OCP (Reformulation)

On a given tier, plateaus are prohibited.

The definition in (11) prohibits successions of: (i) identical feature matrices, (ii) rhythmic units, (iii) identical syllabic components, and (iv). $\emptyset$ (i.e., empty positions/nodes). ${ }^{2}$ Note that the symbol $\emptyset$ should not be seen as an element, but as the absence of an element in a given position.

This reformulation of OCP echoes an analysis of Rowicka (1999) supposing that adjacent empty nuclei are prohibited by a NO LAPSE constraint avoiding adjacent unstressed syllables. Such an analysis is not very different from the OCP-based approach, but I will show that the present proposition makes predictions unexplored so far.

\subsection{Epenthesis is a dissimilative process}

We already saw in section 1 that vowels and consonants are segregated in both ECP and OCP effects. Accordingly, their respective materials are distributed on separated tiers. When two adjacent nuclei are empty, they involve empty nodes on a vowel tier (e.g., the V-place node of Hume 1992). These empty nodes form a plateau in (12a) which is prohibited by the definition of OCP in (11). This ill-formed configuration is thus repaired by means of epenthesis (12b) or deletion (12c). ${ }^{3}$ (In the following figures, empty positions are depicted separately for convenience, but the $\mathrm{C} / \mathrm{V}$ segregation is not accurately represented.)

${ }^{2}$ This is but one of a variety of possible formulations. The discussion here is intended to state a unification of the various avatars of OCP, not its precise formulation. This should be refined in further studies.

${ }^{3}$ One could assume that epenthesis is not an addition of phonological material, but the surface realization of an empty position. In this case, it should not be able to avoid a succession of empty nuclei. However, I want to draw attention to the literature arguing that epenthesis is able to repair configurations violating OCP (see the case of English in (7) and other similar cases in McCarthy 1986). In this respect, I assume that epenthesis is not only a surface realization but also a mechanism belonging to the underlying representation. 
(12)

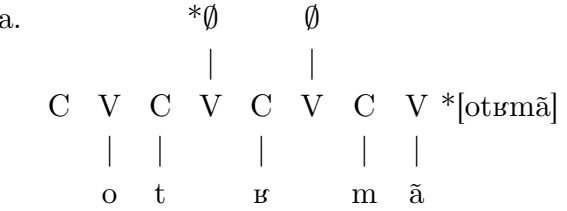

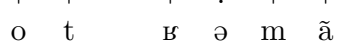

According to this representation, epenthesis and deletion are dissimilative processes in the sense that they aim to prevent a succession of identical (empty) nodes on a given tier. This interpretation strongly relies on the representation of the skeleton defended by the Strict CV framework: before the notion of empty skeletal slot, it was impossible to interpret epenthesis as a dissimilative process. Thus, this hypothesis reduces the number of principal phonological processes (see e.g., Grammont 1933) to assimilation, dissimilation, lenition, fortition and metathesis. Epenthesis and deletion are discarded. ${ }^{4}$

Nevertheless, the OCP-based analysis in (12) faces an issue that should be mentioned. We saw in section 1 that a pair of entities violating OCP should be repaired by changing the right part (e.g., deletion of the second lateral in (8b)), or the left part (centralization of the first vowel in (9b)). However, Government Phonology generally assumes that the site that cannot remain empty is the ungoverned one (i.e., the left one) ${ }^{5}$ Such a directionality of epenthetic processes is not captured by the OCP analysis alone.

Two options can be considered. First, it is possible that the preference for left-insertion is due to the Universal Association Convention

${ }^{4} \mathrm{I}$ am aware that this claim is very strong. It can be adjusted in the future, but I do not want to weaken it without first exploring its potential.

${ }^{5}$ As mentioned earlier, the example of right-insertion in French (see (2), (5) and (12)) is misleading. Scheer $(2000 ; 2001)$ supposes that this vowel is lexical. Hence the absence of expected left-insertion (i.e., *[otəьта̃]). 
(UAC) introduced in Clements \& Sezer (1982). Following this principle, segments associate to skeletal positions from left to right. If one assumes that epenthesis results from an association (see footnote 3 ), then it should appear in the left site.

The second possibility is that the empirical basis for a hypothetical directionality of epenthetic processes is wrong. Itô (1989) mentions that epenthesis can occur on the left or on the right in different varieties of Ara-

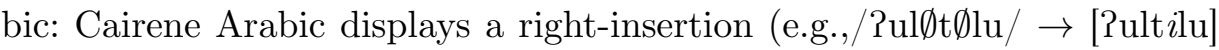
'I said to him'), and Iraqi Arabic displays a left-insertion (e.g.,/gilØtØla/ $\rightarrow$ [gilitla] 'I said to him').

In the context of this paper, I will not express an opinion about these two options. The empirical basis certainly requires further investigations. If a universal preference for left-insertion is confirmed, the UAC-option should be explored. If such a preference is invalidated, then the actual analysis already matches the data. In the meanwhile, I will only point out that ECP does not formally prohibit the possibility of right-insertion either. Admittedly, the definition of ECP in (4) conditions the realization of ungoverned nuclei. However, it does not say anything about the realization of governable nuclei. These can remain empty, but they can also be realized in order to govern the nucleus on their left. This is the case in French (whether the realized vowel is lexical or not) and in Modern Hebrew (see Enguehard \& Faust to appear).

\subsection{Empty onsets are limited by OCP}

In the preceding section, I argued that OCP can do the same as ECP. In this section, I aim to point out what it can additionally do.

As we already saw in section 1, ECP originally aimed to account for the restrictions on consonant clusters by preventing sequences of empty nuclei. By doing this, this principle also rules out such things as superlong geminates (13a), which seldom occur in natural languages (when they do, e.g., in Estonian or Livonian, they are found in very specific contexts; see Enguehard 2016). However, this principle does not say anything about empty onsets and the representation of long vowels. We know that superlong vowels are at least as unusual as super-long geminates, but ECP does not prohibit the succession of empty onsets that is involved in their representation (13b). The restriction on the length of geminates and long vowels is structurally the same: they cannot exceed two positions. However, a government-based analysis (or a competing NO LAPSE-based analysis) needs to introduce another type of relation applying exclusively between 
onsets in order to account for the ill-formedness of the super-long vowel in (13b). Such an option was considered in Carvalho (2002).

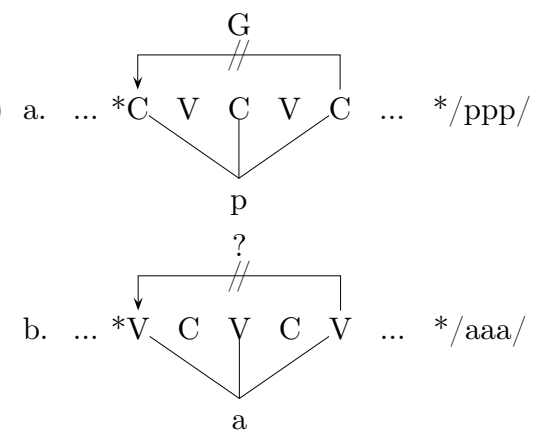

In contrast, the OCP-based analysis accounts for the ill-formedness of both (13a) and (13b) with the same process: a dissimilation between adjacent empty nodes on the vowel tier and the consonant tier respectively (14a-b). This principle rules out: (i) CCC clusters, ${ }^{6}$ (ii) super-long geminates, (iii) super-long vowels, and (iv) successions of hiatuses or such things as "quadriphtongs", "octophtongs", etc.

(14)

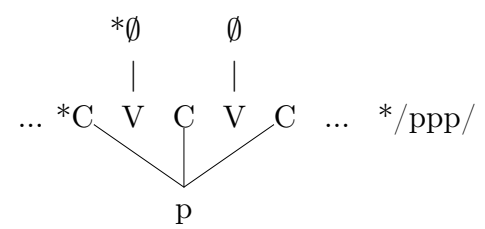

b.

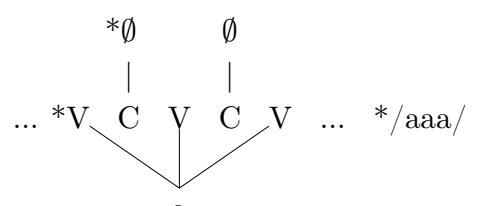

To conclude this section, I showed that OCP can do the same job as ECP in limiting consonant clusters. Additionally, and based on the same theoretical device, it can also restrict vowel length and successions of empty onsets.

${ }^{6}$ Concerning CCC clusters with a branching onset, it can be assumed that the branching onset: (i) is a monopositional complex segment (see Lowenstamm 2003), or (ii) it involves a liquid that fulfills a V position (see Pöchtrager 2001). These two options are acceptable for now, but I intend to refine them in the future. 


\section{Prediction}

In this section, I show that the reformulation of OCP in (11) predicts some specific features of word-edges.

\subsection{The specificity of the word-edges}

We saw in section 2 that OCP in (11) aims to avoid sequences of empty nuclei and sequences of empty onsets (see (14)). These are unusual wordinternally, but they are very common at word-edges. Due to the representation of the skeleton as a periodic sequence of CV units, word-final CC clusters are represented with two empty nuclei (15a), and word-initial long vowels are represented with two empty onsets (15b). As the reader may have already understood, these configurations are ill-formed following the definition of OCP in (11).

(15) a

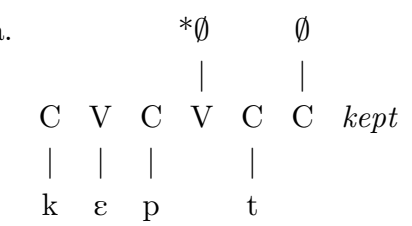

b. $* \emptyset-0$

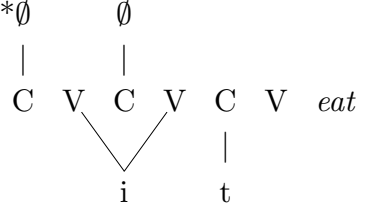

In fact, the configuration in (15a) should also be ruled out by the strict definition of ECP in (4). The penultimate V position should not be governed since it is followed by another empty nucleus. Moreover, the final empty nucleus should not be empty either, since it is not followed by any nucleus. In order to account for these issues, the government-based analysis needs to assume that Final Empty Nuclei have specific properties: (i) they can remain empty without being governed (see Kaye 1990, 314 ), and (ii) they can license and govern without being phonetically expressed (see Charette 1991, 140 and Scheer 1998, 281). Note that this option accounts exclusively for the configuration in (15a). As mentioned before, the government-based analysis is not traditionally concerned with the empty onsets. But if one strives to account for the limitations of empty onsets word-internally (like Carvalho 2002), the configuration in (15b) is 
problematic. Should we introduce another specific category in parallel with Final Empty Nuclei: i.e., Initial Empty Onsets?

The fact is that the specificity of final nuclei and the specificity of initial onsets is related to their peripheral position. The initial onset begins the CVCV string, and the final nucleus ends the CVCV string. Scheer (2000; 2004) assumes that the specificity of Final Empty Nuclei is due to functional reasons: they are the point of departure in the computation of lateral relations. I argue that the specificity of both the final empty nuclei and the initial empty onsets is due to structural reasons: they are specific only because they are peripheral.

We saw in the preceding section that Carvalho (2002) suggested that the CVCV string is not due to the repetition of a CV unit, but to OCP. In other words, a word-internal $\mathrm{V}$ position cannot be removed without violating OCP (i.e., resulting in ${ }^{*} \mathrm{CC}$ ) and a word-internal $\mathrm{C}$ position cannot be removed either without violating OCP (i.e., resulting in ${ }^{*} V V$ ). Hence a strict periodicity CVCV. However, the removal of an initial C position does not trigger any ill-formed ${ }^{*} \mathrm{VV}$, and the removal of a final $\mathrm{V}$ position does not trigger any ill-formed ${ }^{*} \mathrm{CC}$. In other terms, these peripheral positions are specific in the sense that they can be absent without violating OCP. Thus, the optional absence of a final V (16a) or the optional absence of an initial C (16b) accounts for the well-formedness of final CC clusters or initial VV clusters: their representations do not involve any sequence of empty positions. ${ }^{7}$ For similar assumptions (based on different argumentations) about the shape of the skeleton at word-edges, the reader can refer to Dienes \& Szigetvári (1999) and Polgárdi (2009).

(16) a.

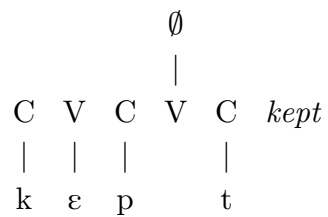

b. $\quad 0$

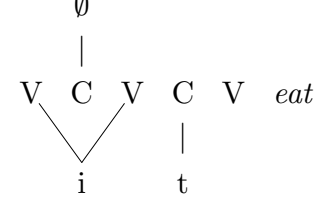

${ }^{7}$ The question whether these peripheral positions are removed or not inserted is an important issue. For now, I cannot express an argued opinion. I leave this question for further studies. Most importantly, their presence is regulated by OCP. Thus the structure of the skeletal string at the periphery is supposed to vary depending on the context, leading to possible sandhi effects. For instance, in order to avoid a *VV configuration, a hypothetical skeletal string originally beginning with a $\mathrm{V}$ position (e.g., eagle) will provide an additional empty $\mathrm{C}$ position if it is preceded by a clitic ending with another $\mathrm{V}$ position (e.g., $a$ ). This emerging $\mathrm{C}$ position is available for floating segments, hence the realization of $/ \mathrm{n} /$ in an eagle. 
This specificity of word-edges is a prediction of my analysis in the sense that I proceeded to a unification of the notions regulating epenthesis and those accounting for the organization of word-edges with only one principle: the definition of OCP in (11). For the skeptic reader who thinks that a hypothetical contrast between an empty position and an absence of position is circular, I move on to the representation of extrametricality in the following section.

\subsection{The extrametricality of final consonants}

The V positions of the Strict CV framework also have a metrical aspect: they represent weight units equivalent to moras (Scheer \& Szigetvári 2005). See the representation of a closed syllable in (17). The nucleus is moraic because it is directly associated to a $\mathrm{V}$ position. The coda is also moraic because it is indirectly associated to a $\mathrm{V}$ position (i.e., it is followed by an empty nucleus). However, the onset is not moraic because the following $\mathrm{V}$ position is already attributed to the vowel material. Thus, the bimoraicity of heavy syllables if derived from the structure of the skeleton.

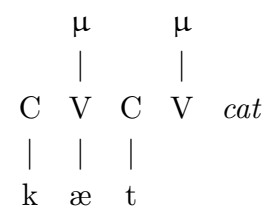

Now see the stress pattern of Lake Miwok (Tranel 1991) in (18). In this language, stress targets the rightmost heavy syllable (18a) (stressed nuclei are underlined). As you can see in (18b), word-internal codas take part in syllable weight. But final closed syllables are not counted as heavy (18c).

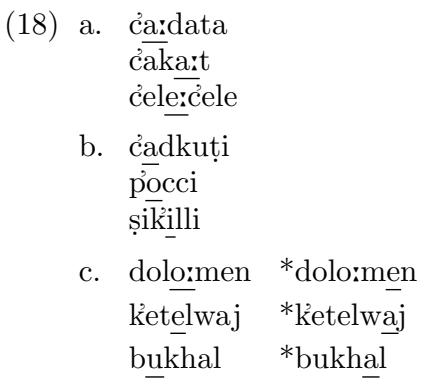

(Tranel 1991)

The extrametricality of final consonants implies that Final Empty Nuclei are unexpectedly weightless in this language (unlike the representation in 
(19a)). This difference between word-internal empty V positions and wordfinal empty $\mathrm{V}$ positions is expected if one assumes (as I did in the preceding section) that the final V position can be absent (19b). In (19b), the final coda is not moraic because it is not followed by an empty nucleus. Thus the final closed syllable is counted as light and stress targets the penultimate syllable.

(19) a.

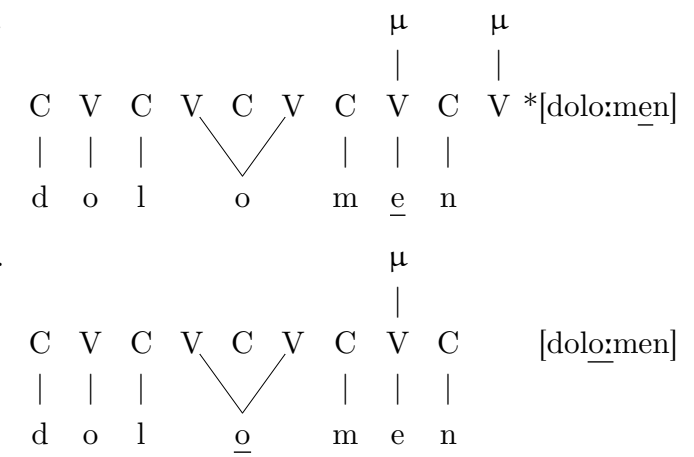

Here, the absence of the final empty nucleus ceases to be circular. An independent surface contrast exists between an empty $\mathrm{V}$ position and an absence of $\mathrm{V}$ position. If empty nuclei are equivalent to weight units, then in the absence of weight, one can suppose an absence of empty nucleus. In conclusion, there are three independent arguments for the optional absence of final empty nuclei: (i) the definition of OCP in (11), (ii) the wellformedness of final CC clusters, and (iii) the optional extrametricality of final consonants.

\subsection{A note on the primitive syllabic structure}

The reader certainly noticed that the analysis that I proposed in this paper supposes that the CVCV string does not necessarily begin with $\mathrm{C}$, and does not necessarily end with $\mathrm{V}$. There are four logical possibilities illustrated in (20). All these configurations are equally well-formed and primitive (see Dienes \& Szigetvári 1999 for another argumentation concerning a primitive VCVC string).

(20) a. CVCVCV

b. VCVCVC

c. $\mathrm{CVCVC}$

d. VCVCV 
Some readers could suppose that this analysis does not capture anymore the fact that $\mathrm{CV}$ is the universal syllable. In fact, my proposition implies that there are no such things as syllables in the underlying representation. However, in the spirit of the Maximal Onset Principle of Kahn (1976) and Selkirk (1981), I assume that a consonant is universally connected to a following vowel in the surface syllabification. ${ }^{8}$ Thus, provided that all their positions are fulfilled, the primitive strings in $(20 \mathrm{a}-\mathrm{d})$ show $\mathrm{V}$ and CVC syllables word-initially and word-finally respectively. But the only pattern that is shared by all these strings is $\mathrm{CV}$. The syllable $\mathrm{V}$ is not observed in (20a, c) and CVC is not observed in (20a, d). In other words, CV is the only universal syllable found in (20).

It goes without saying that not all languages display all the strings in (20a-d). Some (universal or language-specific) parameters still need to be defined. This part of the analysis requires further typological investigations from my part. As for now, this hypothesis predicts the following: a language requiring a filling of all skeletal slots could have: (i) only CV syllables (20a), or (ii) V syllables exclusively at the beginning of the word (20b, d), or (iii) CVC syllables exclusively at the end of the word (20b, c).

\section{Conclusion}

To conclude this paper, I proposed to unify the Empty Category Principle of Government Phonology with another (more general) principle: the Obligatory Contour Principle. I showed that these principles share numerous structural properties: (i) they prevent sequences of identical entities, and (ii) they trigger similar repair mechanisms. The main difference is substantial: ECP handles empty syllabic components, when OCP handles phonological features.

I proposed a broader definition of OCP that includes all phonological entities and I showed to what extent this definition can account for the effects of ECP. I pointed out that OCP can also account for: (i) restrictions on vowel length, and (ii) some specificities of phonology at word-edges. All this results from a unification that can be formulated in more general terms: syllables and epentheses result from dissimilations between empty positions.

Of course, licensing and the role of government in lenition and fortition have to be discussed in further studies (it is already discussed in

${ }^{8}$ Accordingly, the string in e.g., (20b) cannot surface as VC.VC.VC. It will necessarily surface as V.CV.CVC. 
Enguehard \& Luo 2017). In the meanwhile, I highlighted that the Strict CV framework is not an artifact of Government Phonology: it is a theoretical device that aims to move beyond the notion of lateral relations inherited from Government Phonology.

\section{References}

Anderson, Stephen R. 1974. The organization of phonology. New York: Academic Press.

Archangeli, Diana. 1985. Yokuts harmony: Evidence for coplanar representation in nonlinear phonology. Linguistic Inquiry 16. 335-372.

Avanesov, Ruben I. 1949. Ocherki russkoj dialektologii. Moscow: Gosudarstvennoe uchebnopedagogicheskoe izdatel'stvo ministerstva prosveshchenija RSFSR.

Carvalho, Joaquim Brandão de. 2002. De la syllabation en termes de contours cv. Habilitation à diriger des recherches thesis. Ecole des Hautes Etudes en Sciences Sociales.

Charette, Monik. 1991. Conditions on phonological government. Cambridge: Cambridge University Press.

Clements, George N. 1985. The geometry of phonological features. Phonology Yearbook 2. $225-252$.

Clements, George N. and Engin Sezer. 1982. Vowel and consonant disharmony in Turkish. In H. van der Hulst and N. Smith (eds.) The structure of phonological representations, part II. Dordrecht, Cinnaminson: Foris. 213-255.

Delattre, Pierre. 1951. Le jeu de l'e instable intérieur en francais. The French Review 24. $341-351$.

Dienes, Péter and Péter Szigetvári. 1999. Repartioning the skeleton: VC Phonology. Ms., Eötvös Loránd University (ELTE), Budapest.

Enguehard, Guillaume. 2016. Vers une représentation exclusivement squelettale de l'accent: Argumentation à partir de données du same du sud, du live, du norrois et du russe. Doctoral dissertation. University Paris 7.

Enguehard, Guillaume and Noam Faust. to appear. Guttural ghosts in Modern Hebrew. Linguistic Inquiry.

Enguehard, Guillaume and Xiaoliang Luo. 2017. Strength is length. Paper presented at the Twenty-Fifth Manchester Phonology Meeting, 25-27 May 2017.

Grammont, Maurice. 1914. Traité pratique de prononciation française. Paris: Delagrave.

Grammont, Maurice. 1933. Traité de phonétique. Paris: Delagrave.

Hume, Elizabeth. 1992. Front vowels, coronal consonants, and their interaction in nonlinear phonology. Doctoral dissertation. Cornell University.

Itô, Junko. 1989. A prosodic theory of epenthesis. Natural Language \& Linguistic Theory 7. $217-259$.

Kahn, Daniel. 1976. Syllable-based generalisations in English phonology. Doctoral dissertation. MIT, Cambridge, MA. Published by Garland Press, New York, 1980.

Kaye, Jonathan D. 1990. 'Coda' licensing. Phonology 7. 301-330.

Kaye, Jonathan D., Jean Lowenstamm and Jean-Roger Vergnaud. 1990. Constituent structure and government in phonology. Phonology 7. 193-231. 
Leben, William R. 1973. Suprasegmental phonology. Doctoral dissertation. MIT.

Lowenstamm, Jean. 1996. CV as the only syllable type. In J. Durand and B. Laks (eds.) Current trends in phonology. Models and methods. Salford: European Studies Research Institute, University of Salford Publications. 419-441.

Lowenstamm, Jean. 2003. A propos des gabarits. Recherches Linguistiques de Vincennes 32. $7-30$.

McCarthy, John J. 1986. OCP effects: Gemination and antigemination. Linguistic Inquiry 51. 207-263.

Odden, David. 1994. Adjacency parameters in phonology. Language 70. 289-330.

Polgárdi, Krisztina. 2009. Trochaic proper government, loose CV and vowel $\sim$ zero alternation in Hungarian. In M. den Dikken and R. M. Vago (eds.) Approaches to Hungarian 11: Papers from the 2007 New York conference. Amsterdam \& Philadelphia: John Benjamins. 143-165.

Pöchtrager, Markus. 2001. Finnish consonant gradation. MA thesis. University of Vienna.

Prince, Alan S. 1983. Relating to the grid. Linguistic Inquiry 14. 19-100.

Rowicka, Grażyna. 1999. On ghost vowels: A Strict CV approach. The Hague: Holland Academic Graphics.

Scheer, Tobias. 1996. Une théorie de l'interaction directe entre consonnes. Contribution au modèle syllabique CVCV, alternances e- $\emptyset$ dans les préfixes tchèques, structure interne des consonnes et la théorie X-barre en phonologie. Doctoral dissertation. Université Paris 7, Paris.

Scheer, Tobias. 1998. Governing domains are head-final. In E. Cyran (ed.) Structure and interpretation. Studies in phonology (PASE Studies \& Monographs 4). Lublin: Wydawnictwo Folium. 261-285.

Scheer, Tobias. 2000. De la localité, de la morphologie et de la phonologie en phonologie. Habilitation thesis. Université de Nice.

Scheer, Tobias. 2001. A propos de la vie des yers en slave et en français. Travaux du Cercle de Linguistique de Nice 20. 143-230.

Scheer, Tobias. 2004. A lateral theory of phonology. Vol 1: What is CVCV, and why should it be? Berlin \& New York: Mouton de Gruyter.

Scheer, Tobias and Péter Szigetvári. 2005. Unified representations for stress and the syllable. Phonology 22. 37-75.

Selkirk, Elisabeth O. 1981. English compounding and the theory of word-structure. In M. Moortgat, H. van der Hulst and T. A. Hoekstra (eds.) The scope of lexical rules. Dordrecht: Foris. 229-277.

Steriade, Donca. 1987. Redundant values. In A. Bosch, B. Need and E. Schiller (eds.) CLS 23-II: Papers from the Parasession on Autosegmental and Metrical Phonology. Chicago: Chicago Linguistic Society,. 339-362.

Tranel, Bernard. 1991. CVC light syllables, geminates and moraic theory. Phonology 8. 291-302.

Yip, Moira. 1988. The Obligatory Contour Principle and phonological rules: A loss of identity. Linguistic Inquiry 19. 65-100. 